\title{
Efeito da adição de resíduos da construção e demolição (RCD) nas propriedades hidromecânicas de um solo areno-argiloso
}

\section{Effect of construction and demolition waste (CDW) addition on the hydromechanical properties of a sandy-clayey soil}

Aline Cátia da Silva ${ }^{1}$, Stela Fucale ${ }^{1}$, Silvio Romero de Melo Ferreira ${ }^{2}$

\footnotetext{
${ }^{1}$ Universidade de Pernambuco - UPE, CEP: 50720-001, Recife, Pernambuco, Brasil.

e-mail: alinecatia.catia@gmail.com, sfucale@yahoo.com.br

${ }^{2}$ Universidade Federal de Pernambuco - UFPE, CEP: 50740-530, Recife, Pernambuco, Brasil.

e-mail: sr.mf@hotmail.com
}

\section{RESUMO}

Diante de uma produção cada vez mais evidente dos resíduos sólidos resultantes das ações humanas, tais como os Resíduos da Construção e Demolição (RCD), destinar adequadamente estes materiais tem ganho importância no cenário atual, pois quando dispostos irregularmente atuam de forma degradante sobre o meio ambiente e contribuem com a proliferação de vetores de doenças. Sob outra perspectiva, os problemas enfrentados pela Construção Civil na busca por áreas cujos solos apresentem propriedades favoráveis para utilização em obras de engenharia, têm incentivado o melhoramento dos solos com características insatisfatórias. Sendo assim, este artigo tem por objetivo analisar a influência de agregados miúdos reciclados de RCD nas propriedades hidromecânicas de um solo areno-argiloso, em diferentes teores de substituição (10, 20 e 30\%). Para tanto, os materiais utilizados foram submetidos a ensaios laboratoriais de caracterização física de solos, compactação na energia Proctor normal, caracterização microestrutural, cisalhamento direto e permeabilidade das amostras compactadas na condição ótima de compactação. Os resultados obtidos mostram que para o solo utilizado, a adição de agregado reciclado de RCD reduz as suas frações finas e a plasticidade, pouco interfere na massa específica dos grãos, diminui em até $2 \%$ a umidade ótima, com uma baixa variação do peso específico aparente seco, e mantêm a faixa de valores dos parâmetros de resistência, todavia se verifica um acréscimo no coeficiente hidráulico do solo em mais de 13 vezes. As diferenças de comportamento hidráulico podem ser explicadas por mudanças observadas na microestrutura das amostras.

Palavras-chave: Resíduos da Construção e Demolição; Melhoramento de solo; Permeabilidade; Cisalhamento direto.

\section{ABSTRACT}

As the production of solid waste resulting from human actions, such as Construction and Demolition Waste (CDW), has continually increased, proper disposal of these materials has become critically important, because when improperly disposed, they degrade the environment and contribute to the proliferation of disease vectors. The construction industry has also faced difficulties in searching for areas with soils suitable for use in engineering projects, leading to efforts to improve soils having unsatisfactory characteristics. This study aims to analyze the influence of recycled CDW aggregates on the hydromechanical properties of clay-sand soil at different substitution levels $(10,20$, and 30\%). To achieve this, the materials used were submitted to a variety of laboratory tests: physical characterization, normal Proctor energy compaction, microstructural characterization, direct shear, and permeability of the compacted samples under optimum compaction conditions. The results show that for the soil used, the addition of recycled CDW aggregate reduces its fine fractions and plasticity, interferes minimally in the real specific weight, decreases the optimal humidity by up to $2 \%$, with a low variation of the apparent dry specific weight, keeps within the range of values for the re- 
sistance parameters, and increase in the hydraulic coefficient of the soil by more than 13 times. The differences in hydraulic behavior can be explained by observed changes in the microstructure of the samples.

Keywords: Construction and demolition waste; Soil improvement; Permeability; Direct shear.

\section{INTRODUÇ̃̃O}

As atividades humanas têm contribuído com o aumento da geração de resíduos sólidos, seja individual ou coletivamente, devido ao modelo de consumo praticado. Frente a isso, existe a problemática do descarte destes materiais, a citar os Resíduos da Construção e Demolição (RCD), que são responsáveis por diversos problemas ao serem dispostos irregularmente próximos a locais públicos, como terrenos baldios, corpos hídricos e vias de tráfego, atraindo o descarte de outros resíduos para estes ambientes e contribuindo com a proliferação de vetores de doenças.

Os RCD são gerados em construções, reformas, reparos, assim como resultantes de escavações de terrenos, sejam provenientes de empresas de pequeno a grande porte ou por geradores informais. Essas diferenças, apesar de influenciarem na diversidade dos componentes dos RCD, não reduzem a possibilidade de reutilização destes resíduos, pois o seu potencial de reciclagem pode atingir até $91 \%$ [1,2].

Por outro lado, a carência na disponibilidade de áreas cujos solos apresentem propriedades adequadas para utilização em obras de engenharia torna-se preocupante, visto a escassez de matérias-primas não renováveis e os materiais locais, muitas vezes, não possuírem características satisfatórias. Este cenário abre a possibilidade de melhorar as características do solo componente dessas áreas, tais como densidade, resistência e permeabilidade, criando assim um novo material. Para isso, podem ser empregados processos de estabilização de solos.

Dentre os tipos de estabilização disponíveis, existe o método de origem física ou mecânica, que envolve processos como, por exemplo, estabilização granulométrica e rearranjo das partículas por compactação [3]. O melhoramento de solos com agregados tem se enquadrado cada vez mais na tecnologia dos materiais compósitos, sendo estes originados da combinação de dois ou mais elementos diferentes, cujas propriedades não são encontradas nos materiais de origem, uma vez que suas características são otimizadas [4, 5].

Os resíduos provenientes das atividades construtivas podem ser aplicados como agregados reciclados, sendo estes definidos como materiais com características granulares e que ao passar por um processo de beneficiamento exibem propriedades técnicas aceitáveis para aplicações em obras de engenharia [6]. Dessa forma, os agregados reciclados de RCD têm sido empregados em diversas áreas, em virtude da sua resposta positiva de adaptabilidade as técnicas amplamente difundidas na construção civil, inclusive no reforço de solos, por meio de sua estabilização granulométrica, proporcionando a estes menores deformações e melhores características resistentes.

Autores como Ferreira e Tomé [7], verificaram a utilização de agregados provenientes de RCD como alternativa de melhoramento de um solo de basalto para ser aplicado em camadas na base de fundações superficiais, obtendo como resultado o aumento da capacidade de carga e redução do recalque do solo que se encontrava na base da fundação.

Já Dias [8], que utilizou agregados reciclados de RCD misturados a um solo tropical, visou analisar a viabilidade técnica do novo material em sistemas de cobertura de aterros sanitários; enquanto Santos [9], ao avaliar a aplicação de diferentes amostras de agregado reciclado de RCD em estruturas de solo reforçado, como material de preenchimento, obteve um bom desempenho mecânico; e Macedo [10], que inseriu agregados de RCD como elemento de reforço em um solo areno-argiloso, com o intuito de melhorar os seus parâmetros de resistência.

A busca por opções que proporcionem a melhoria das características de solos com certas inapropriações para serem aplicados em atividades de construção, assim como a oferta de uma adequada destinação dos resíduos sólidos provenientes das ações humanas, a exemplo dos resíduos oriundos da construção civil, torna possível a associação do solo a esses materiais alternativos, mitigando assim os problemas que envolvem tais materiais. Contudo, faz-se necessário investigar as características dos compósitos formados para se compreender a mobilização do conjunto $[11,12]$, haja vista que nem todas as misturas atendem aos critérios técnicos pertinentes.

Nesse contexto, o objetivo do presente estudo é analisar as propriedades hidromecânicas de um solo areno-argiloso com a incorporação de diferentes teores de agregados reciclados de RCD, bem como identificar as limitações destes elementos quando associados, visto que o solo, amplamente utilizado como material de construção, se apresenta susceptível muitas vezes as ações de agentes externos como a água e solicitações de diversos carregamentos. 


\section{MATERIAIS E MÉTODOS}

São apresentados os materiais investigados e descritos os ensaios laboratoriais realizados.

\subsection{Materiais}

O solo utilizado possui textura areno-argilosa e foi coletado de uma encosta denominada Alto do Reservatório, situada em Recife-PE, Figura 1-a. O terreno desta localidade possui sedimentos não consolidados da Formação Barreiras. O agregado miúdo reciclado de RCD enquadra-se na Classe II B (não perigoso e inerte), conforme NBR 10004 [13], e provém de uma usina de beneficiamento localizada no município de Camaragibe-PE, Figura 1-b.

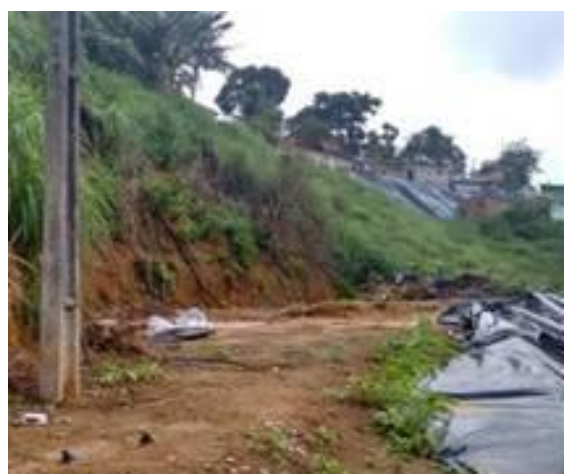

(a)

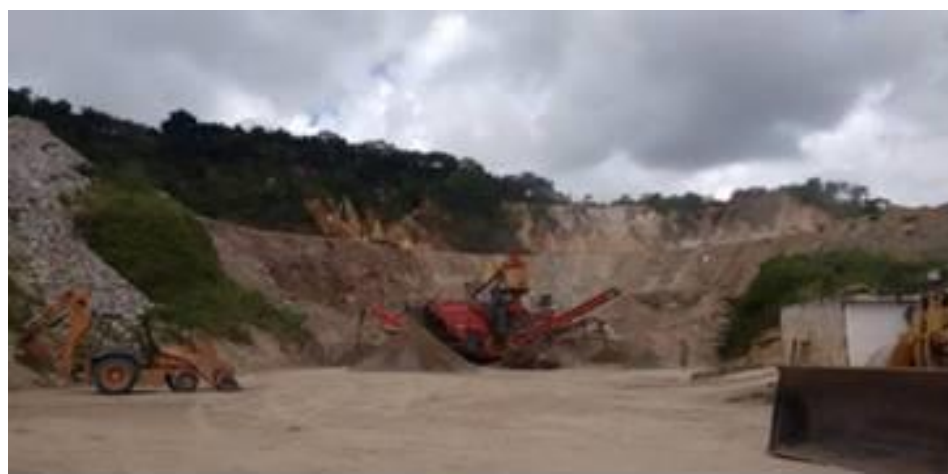

(b)

Figura 1: Local de coleta do solo (a) e vista geral da usina de reciclagem (b).

\subsection{Métodos}

Foram realizadas adições de agregados miúdos reciclados de RCD à massa de solo seca, nas porcentagens de 10, 20 e 30\%, sendo tais misturas denominadas S90/R10, S80/R20 e S70/R30, respectivamente. As amostras de solo, agregado reciclado e misturas de solo com RCD foram submetidas a ensaios de caracterização geotécnica, tais como granulometria por peneiramento e sedimentação, conforme a NBR 7181 [14], massa específica real dos grãos, segundo a NBR 6508 [15], limite de liquidez, de acordo com a NBR 6459 [16], e limite de plasticidade, seguindo as especificações da NBR 7180 [17].

Ensaios de compactação foram executados, segundo as prescrições da NBR 7182 [18], para se obter a umidade ótima e o peso específico aparente seco máximo das amostras na energia de Proctor normal, cujos valores foram utilizados para a moldagem dos corpos de prova nos ensaios de cisalhamento direto e de permeabilidade à carga variável.

A microestrutura das amostras foi observada a partir de ensaios de Microscopia Eletrônica de Varredura (MEV), em um equipamento JSM 6460 Scanning Electron Microscope (SEM), de marca Jeol, a uma voltagem de $30 \mathrm{kv}$. As amostras foram extraídas, cuidadosamente, da parte interior dos corpos de prova provenientes do ensaio de cisalhamento direto, colocadas para secar ao ar e fixadas em um suporte metálico (diâmetro de $75 \mathrm{~mm}$ e altura aproximada de $10 \mathrm{~mm}$ ) por meio de uma fita adesiva de carbono. As superfícies das amostras foram revestidas com uma película fina de carbono.

Para a determinação do coeficiente de permeabilidade do solo, do agregado reciclado de RCD e das misturas, foram realizados ensaios com permeâmetros de carga variável, seguindo os procedimentos da NBR 14545 [19]. Após a moldagem, os corpos de prova foram submetidos à saturação, durante um período de 48 horas, de forma que todos os vazios das amostras ficassem completamente preenchidos com água, para que se pudesse proceder os ensaios de permeabilidade. Os coeficientes hidráulicos foram obtidos pela média de 3 ensaios para cada amostra.

Os ensaios de cisalhamento direto foram realizados em um equipamento com capacidade de $500 \mathrm{kgf} \mathrm{e}$ sensibilidade de $0,001 \mathrm{~mm}$. Todo o procedimento de ensaio foi conduzido de acordo com a norma ASTM D 3080 [20], sendo utilizada uma caixa cisalhante bipartida na horizontal, com área de $10 \mathrm{~cm} \mathrm{x} 10 \mathrm{~cm}$. Neste estudo, a velocidade empregada para o ensaio foi de $0,083 \mathrm{~mm} / \mathrm{s}$ e as tensões normais pré-definidas foram 50 , 100,150 e $200 \mathrm{kPa}$. A etapa de consolidação teve duração de 1 hora, período suficiente para que as deformações fossem praticamente constantes, sendo estas acompanhadas através do sensor de leitura vertical do equipamento de cisalhamento. 


\section{RESULTADOS E DISCUSSÕES}

São apresentados os resultados de caracterização física, compactação, análise microestrutural e comportamentos hidráulico e mecânico do solo, do agregado reciclado de RCD e das misturas formadas.

\subsection{Caracterização física e compactação}

As curvas de distribuição granulométrica dos materiais estudados são apresentadas na Figura 2. Com base nos resultados dos ensaios de granulometria, foram obtidas as seguintes frações granulométricas do solo natural: $13 \%$ de pedregulho; $46 \%$ de areia; $3 \%$ de silte e $38 \%$ de argila, conforme escala da ASTM [21]. O agregado reciclado de RCD é composto por 79\% de grãos equivalentes a areia (tamanhos entre 0,074 mm e 5 $\mathrm{mm}$ ) e $21 \%$ de material que passa na peneira de número 200 (abertura de $0,074 \mathrm{~mm}$ ), de acordo com a escala da ASTM.

As curvas granulométricas das misturas apresentam uma variação em relação às do solo e do agregado reciclado, situando-se entre as curvas dos materiais de origem. $\mathrm{O}$ agregado de $\mathrm{RCD}$ reduziu as frações de silte e argila do solo $(<0,074 \mathrm{~mm})$, todavia exerceu uma maior influência na fração de areia, aumentando-a.

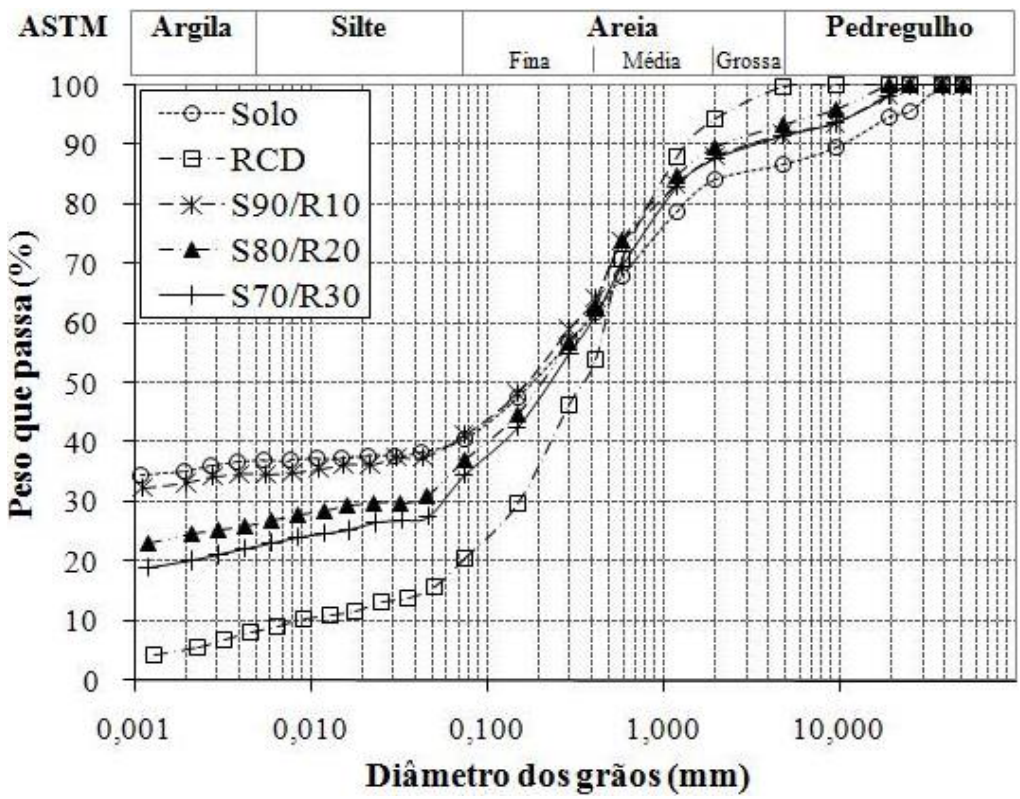

Figura 2: Curvas de distribuição do tamanho das partículas enquadradas na escala granulométrica da ASTM.

Os valores de massa específica real dos grãos, limites de Atterberg e os índices obtidos no ensaio de compactação são apresentados na Tabela 1, seguida pela Figura 3, que apresenta as curvas de compactação do solo, agregado reciclado de RCD e das misturas preparadas para este estudo, utilizando a energia de Proctor normal.

Tabela 1: Parâmetros geotécnicos das amostras investigadas.

\begin{tabular}{|c|c|c|c|c|c|c|}
\hline \multirow{2}{*}{\multicolumn{2}{|c|}{ PARÂMETROS }} & \multicolumn{5}{|c|}{ AMOSTRA } \\
\hline & & \multirow{2}{*}{$\begin{array}{l}\text { SOLO } \\
26,60 \\
\end{array}$} & \multirow{2}{*}{$\frac{\text { RCD }}{26,40}$} & \multirow{2}{*}{$\begin{array}{l}\text { SOLO+10\%RCD } \\
26,60\end{array}$} & \multirow{2}{*}{$\begin{array}{l}\text { SOLO+20\%RCD } \\
26,50\end{array}$} & \multirow{2}{*}{$\begin{array}{l}\text { SOLO+30\%RCD } \\
26,40\end{array}$} \\
\hline Massa específica real & $\operatorname{los}\left(\mathrm{kN} / \mathrm{m}^{3}\right)$ & & & & & \\
\hline \multirow{3}{*}{ Limites de Atterberg } & LL (\%) & 44 & - & 35 & 31 & 28 \\
\hline & LP $(\%)$ & 23 & - & 21 & 18 & 18 \\
\hline & IP $(\%)$ & 21 & NP & 14 & 13 & 10 \\
\hline \multicolumn{2}{|l|}{ Umidade ótima (\%) } & 17,49 & 13,52 & 16,22 & 15,42 & 15,39 \\
\hline \multicolumn{2}{|c|}{$\begin{array}{l}\text { Peso específico aparente seco máximo } \\
\left(\mathrm{kN} / \mathrm{m}^{3}\right)\end{array}$} & 17,60 & 18,72 & 17,63 & 17,87 & 17,97 \\
\hline \multicolumn{2}{|l|}{ Porosidade (\%) } & 34 & 29 & 34 & 33 & 32 \\
\hline
\end{tabular}

Obs.: LL - limite de liquidez; LP - limite de plasticidade; IP - índice de plasticidade; NP - não plástico. 


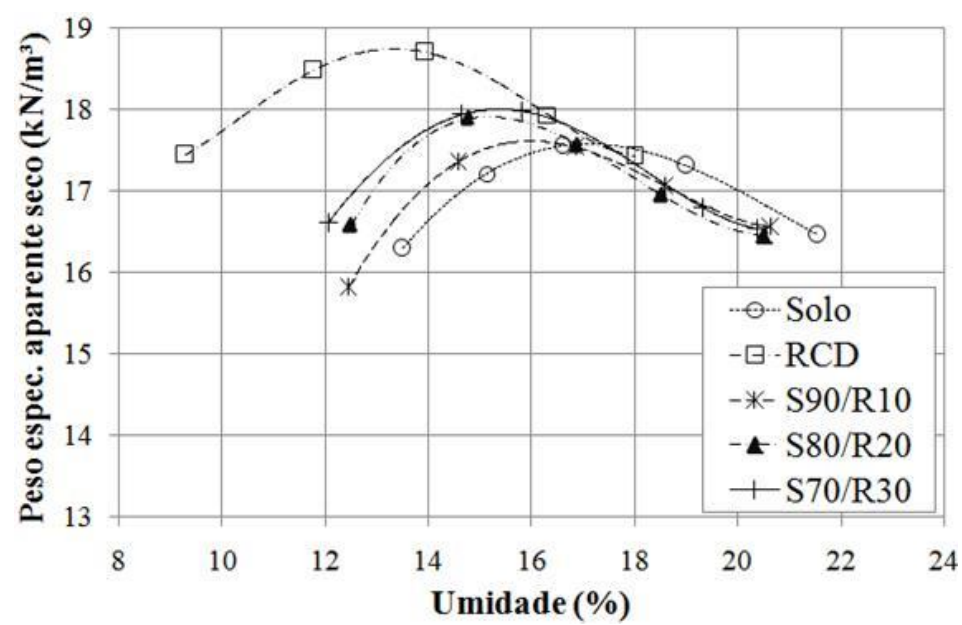

Figura 3: Curvas de compactação para as amostras de solo, agregado reciclado de RCD e misturas.

A massa específica real dos grãos do solo praticamente não é modificada pela inserção do agregado de $\mathrm{RCD}$, uma vez que a densidade do agregado reciclado é próxima a do solo. O solo possui alta plasticidade (IP> $15 \%$ ), enquanto que o agregado reciclado de RCD é não plástico. A adição do RCD ao solo causou uma redução na plasticidade das misturas de $21 \%$ para $10 \%$, Tabela 1 , tornando a plasticidade média.

De acordo com o SUCS (Sistema Unificado de Classificação de Solos) o solo é classificado como uma areia-argilosa (SC), o agregado de RCD equipara-se a um solo do grupo SM (areia-siltosa) e todas as misturas se classificam como areias-argilosas. Pelo sistema TRB (Transportation Research Board) o solo é um material argiloso do tipo A-7-6, o agregado de RCD enquadra-se no grupo A-2-4 e as misturas de solo com 10, 20 e 30\% de RCD pertencem as classes A-6, A-2-6 e A-2-4, respectivamente. Isso indica que a adição do agregado reciclado de RCD tende a melhorar as características do solo para uso como subleito de pavimentos, à medida que o teor de agregado reciclado aumenta, uma vez que o comportamento do solo enquanto subleito passa de sofrível a mal para excelente a bom, conforme o TRB.

A amostra de agregado reciclado de RCD apresenta um peso específico aparente seco máximo superior ao do solo, devido a distribuição das suas partículas se encontrar mais graduada, existindo uma melhor acomodação dos grãos ao longo do processo de compactação, e um menor valor de umidade ótima, visto o baixo teor de finos no agregado reciclado, o que reduz a superfície específica e, consequentemente, a umidade nesse material.

As curvas das misturas são mais altas e deslocadas para a esquerda, Figura 3, ou seja, a adição do agregado reciclado ao solo resultou na redução da umidade ótima das misturas, em até $2 \%$, na diminuição da porosidade e no aumento do peso específico aparente seco máximo, porém a variação é pequena, Tabela 1. Este resultado já era esperado, tendo-se em vista que está se adicionando ao solo um material com peso específico superior e com menor umidade ótima, conforme antes mencionado. Comportamento semelhante foi relatado por outros autores $[8,10,22]$ ao incorporarem agregados reciclados a matriz dos solos.

\subsection{Análise Microestrutural}

As eletromicrografias das amostras de solo e do agregado reciclado de RCD, com aumentos sucessivos de 100x, 500x e 1000x, são apresentadas na Figura 4.

A estrutura do solo compactado é constituída por agregados naturais com grãos subarredondados a arredondados inseridos em uma matriz argilosa, Figura 4-a-b, evidenciando a presença de flóculos com arranjos de grãos de areia interligados por partículas de silte e argila de forma densa, devido ao processo de compactação, Figura 4-c, conferindo ao solo um arranjo de baixa permeabilidade (item 3.3). A forma dos grãos do solo é compatível com o processo de formação dos solos (Formação Barreiras).

$\mathrm{O}$ agregado reciclado de RCD compactado apresenta uma estrutura superficial irregular, Figura 4-d. Observa-se a existência de partículas finas (material pulverulento do RCD) que formam uma película revestindo os agregados, Figura 4-e. O RCD é composto por agregados que não se conectam entre si, formando uma estrutura granular com pequenas floculações esparsas, Figura 4-f. Há uma maior densidade de partículas no agregado reciclado de RCD do que no solo, isto também pode ser comprovado pelo menor índice de vazios (item 3.3) e maior peso específico seco (item 3.1) do agregado de RCD se comparado a areia argilosa. 
Uma comparação das eletromicrografias das amostras de solo com o agregado reciclado e as misturas, nas proporções de 10, 20 e 30\% de adição de agregado de RCD, é apresentada na Figura 5, sendo as imagens ampliadas em 70x. As misturas de solo com agregado reciclado apresentam reentrâncias e saliências em suas superfícies de forma mais acentuada do que no solo, Figura 5-c-d-e. As partículas do solo mais finas se agregam as partículas do RCD, formando flóculos com diferentes formas e grumos de maiores dimensões, o que propicia a ocorrência de caminhos preferenciais de percolação de água, resultando, consequentemente, no aumento da permeabilidade do solo (item 3.3).

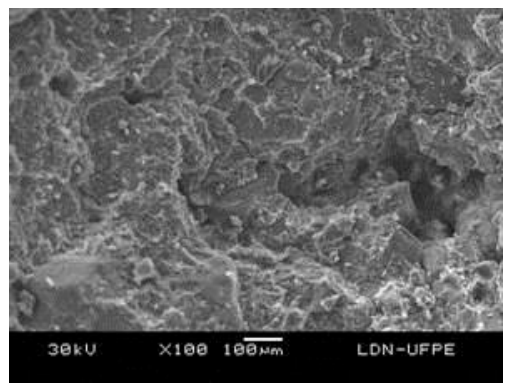

(a)

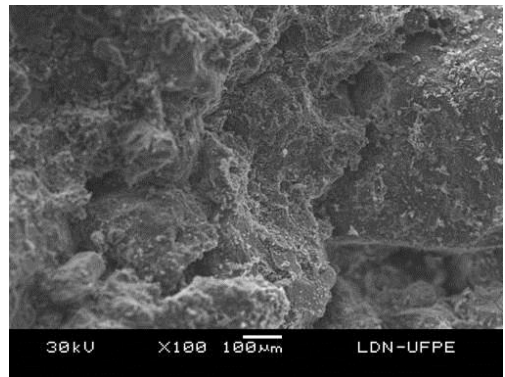

(d)

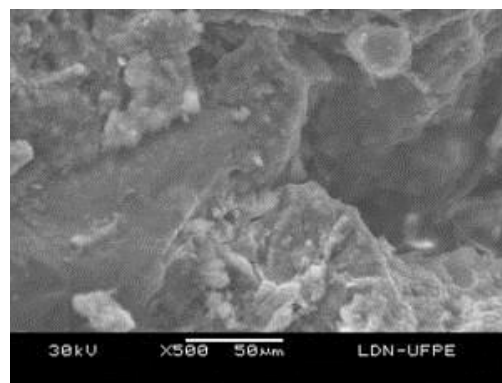

(b)

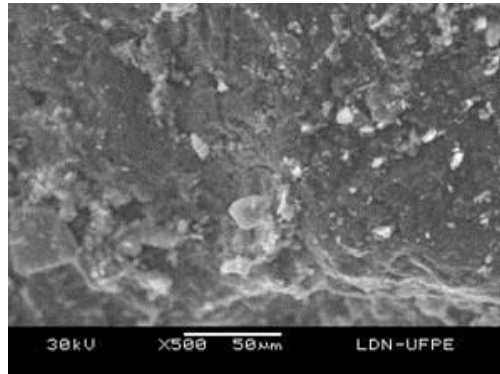

(e)

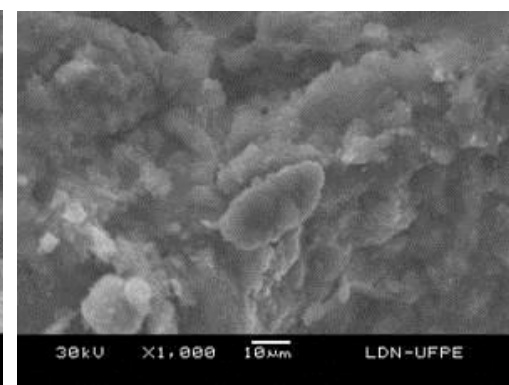

(c)

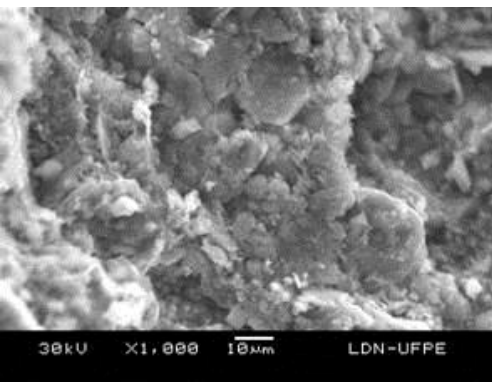

(f)

Figura 4: Eletromicrografias do solo com aumentos de 100x (a), 500x (b) e 1000x (c) e do agregado reciclado de RCD com aumentos de 100x (d), 500x (e) e 1000x (f).

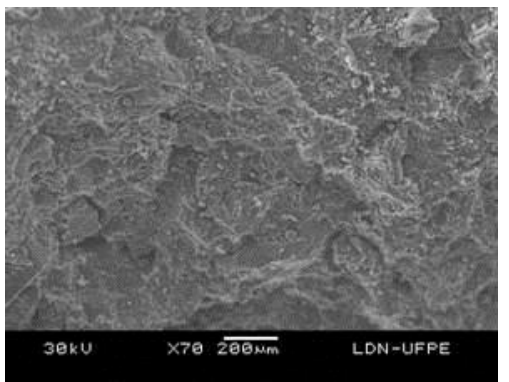

(a)

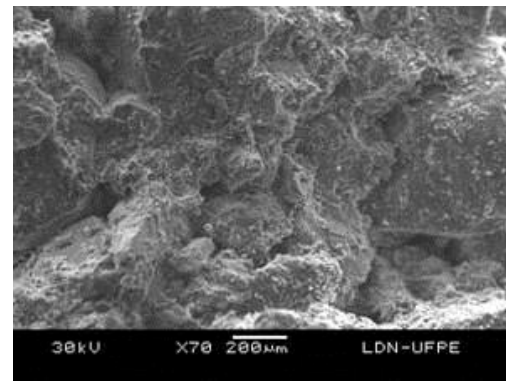

(b)

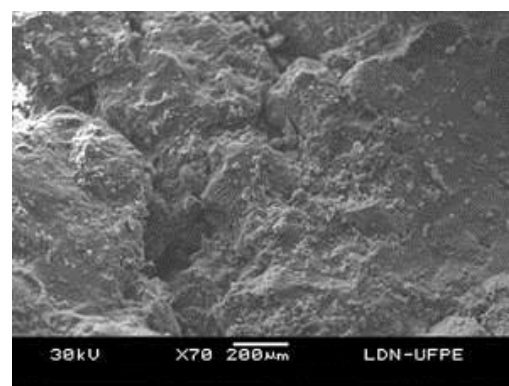

(c)

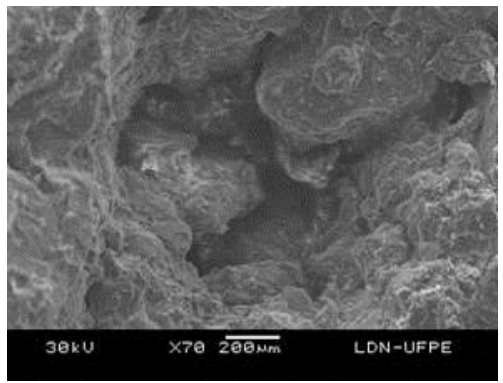

(d)

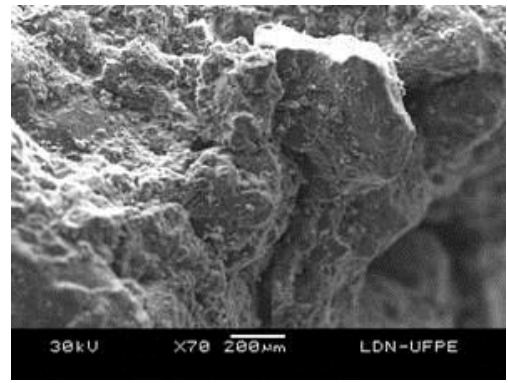

(e)

Figura 5: Eletromicrografias, ampliadas em 70x, do solo (a), agregado reciclado de RCD (b) e misturas de solo com 10\% (c), $20 \%$ (d) e $30 \%$ (e) de agregado reciclado de RCD. 


\subsection{Condutividade hidráulica}

A variação do coeficiente de permeabilidade do solo com a inserção dos diferentes teores de agregado reciclado de RCD é apresentada na Figura 6. O valor médio da condutividade hidráulica do solo saturado foi de $9,31 \times 10^{-10} \mathrm{~m} / \mathrm{s}$, o que indica a sua baixa permeabilidade, podendo ser utilizado como barreira natural impermeabilizante em bases e coberturas de aterros sanitários, pois atende aos requisitos para barreira hidráulica $(<$ $1 \times 10^{-9} \mathrm{~m} / \mathrm{s}$ ), conforme a USEPA [23], devido ao arranjo granulométrico que possui.

A condutividade hidráulica do agregado reciclado de $\operatorname{RCD}\left(6,16 \times 10^{-8} \mathrm{~m} / \mathrm{s}\right)$ se enquadra no intervalo das areias muito finas e siltes, misturas de ambos e argila $\left(10^{-5}\right.$ a $\left.10^{-9} \mathrm{~m} / \mathrm{s}\right)$, segundo Caputo e Caputo [24] e pode ser utilizado em cobertura de aterros para resíduos sólidos não perigosos [25, 26]. Este resultado mostra que o agregado reciclado de RCD possui características hidráulicas próximas a de agregados naturais.

O coeficiente hidráulico do solo sofre um acréscimo quando misturado com o agregado reciclado de RCD, Figura 6-a, superando em mais de 13 vezes o valor obtido para o solo separadamente. Ressalta-se que a inserção de agregado de RCD ao solo facilita a redução da pressão neutra, gerando um efeito associado a dissipação desta pressão mais rapidamente, podendo as misturas serem aplicadas em obras de compactação. Há uma redução do índice de vazios do solo com a incorporação do agregado reciclado, Figura 6-b, porém a condutividade hidráulica cresce devido ao aumento das floculações e grumos formados nas misturas, que propiciam caminhos preferenciais de percolação. A variação do valor da permeabilidade entre as misturas é pequena, demonstrando que as características hidráulicas das misturas formadas são semelhantes.

Cabe ressaltar que, todas as misturas podem compor camadas de cobertura para aterros de resíduos não perigosos [25, 26], entretanto, conforme a NBR 13896 [27], a única mistura que pode ser aplicada em bases de aterros de resíduos sólidos é a S90/R10, visto que possui uma permeabilidade inferior a $1 \times 10^{-8} \mathrm{~m} / \mathrm{s}$, Figura 6. Observa-se ainda que o solo e as misturas concordam com as suas classificações como areias argilosas (SC), assim como o agregado reciclado de RCD como areia siltosa (SM), por apresentarem coeficientes hidráulicos típicos de uma areia com uma porção considerável de partículas finas.

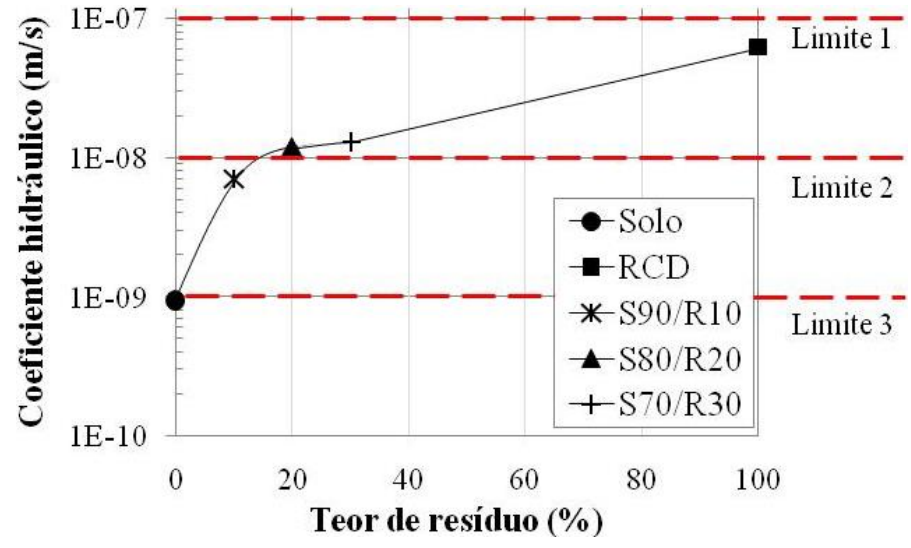

(a)

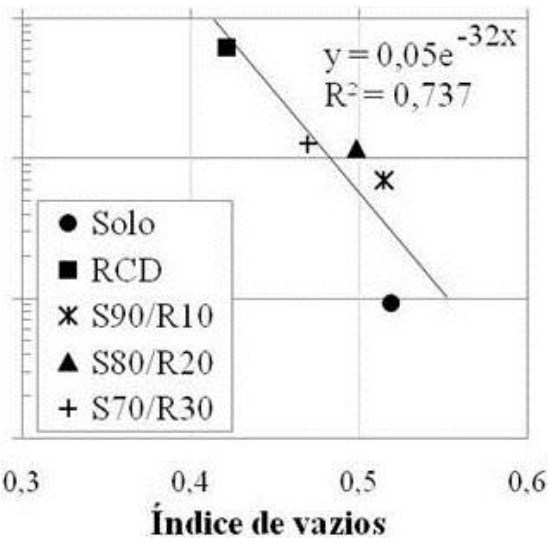

(b)

Obs.: Limite 1 - permeabilidade para coberturas de aterros de resíduos não perigosos [25, 26]; Limite 2 - permeabilidade para bases de aterros de resíduos sólidos [27]; Limite 3 - permeabilidade para barreira impermeabilizante em aterros sanitários [23]; $\mathrm{R}^{2}$ - coeficiente de determinação.

Figura 6: Variação do coeficiente hidráulico com o teor de agregado reciclado de RCD (a) e o índice de vazios (b).

\subsection{Resistência ao cisalhamento}

As curvas de tensão cisalhante versus deslocamento horizontal ( $\tau \mathrm{x} \mathrm{dh}) \mathrm{e}$ de deslocamento vertical versus deslocamento horizontal ( $\mathrm{dh} \mathrm{x} \mathrm{dv}$ ) das amostras investigadas nas tensões normais empregadas (50, 100, $150 \mathrm{e}$ $200 \mathrm{kPa}$ ) estão apresentadas na Figura 7. Vale salientar que as amostras que não apresentam curvas de $\tau$ x dh com um comportamento de pico bem definido tiveram suas tensões cisalhantes de ruptura obtidas a partir do momento em que as curvas $\tau \mathrm{x}$ dh apresentam uma inclinação razoavelmente constante, conforme definido por De Campos e Carrillo [28], Figura 8, sendo este o critério de ruptura adotado neste estudo.

As tensões máximas de cisalhamento (tensões de ruptura) para cada tensão normal imposta permitem a elaboração das envoltórias de Mohr-Coulomb, Figura 9, e, consequentemente, a obtenção do ângulo de atrito e da coesão dos materiais ensaiados. Os resultados dos ensaios de cisalhamento direto estão compilados na Tabela 2. 

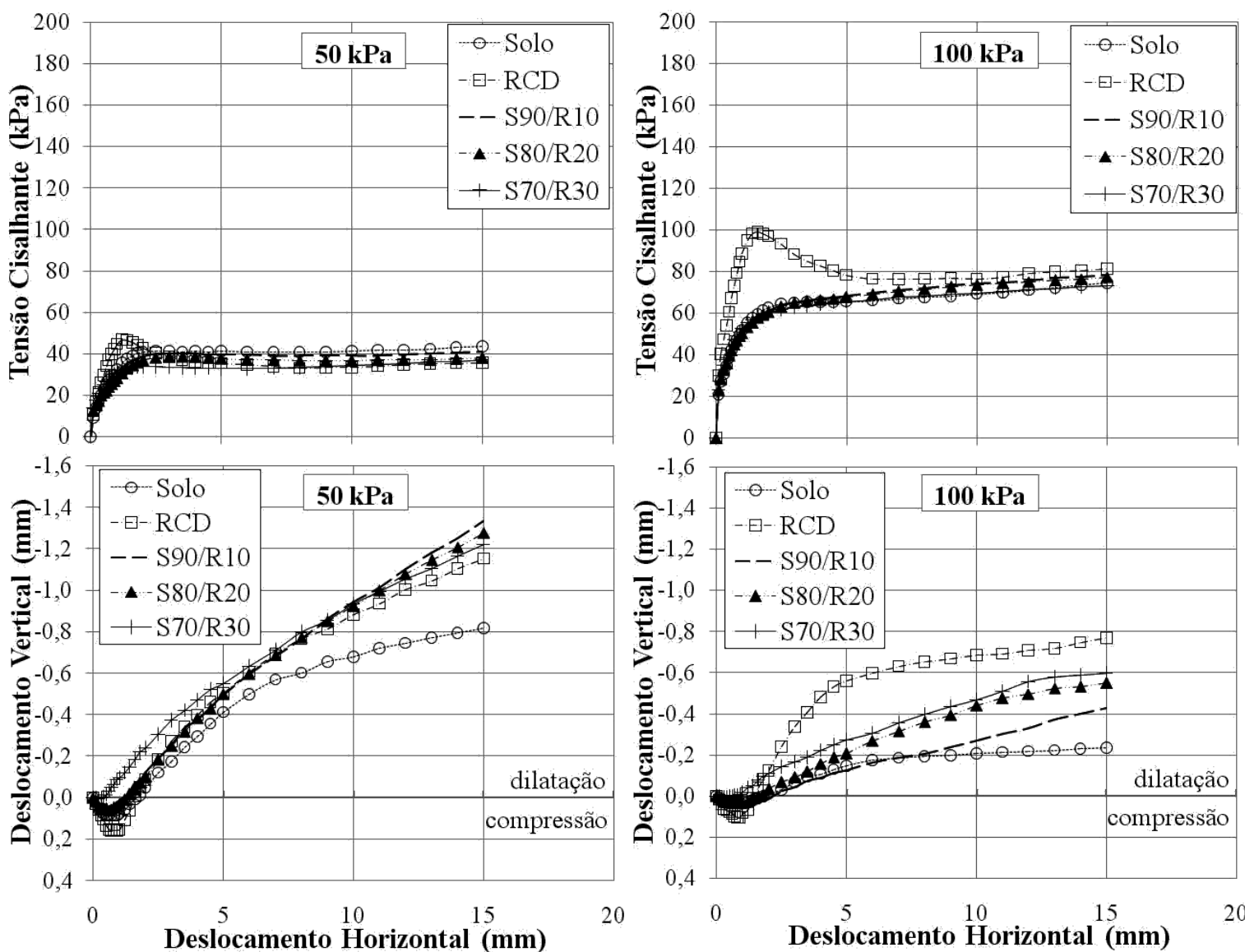

(a)

(b)
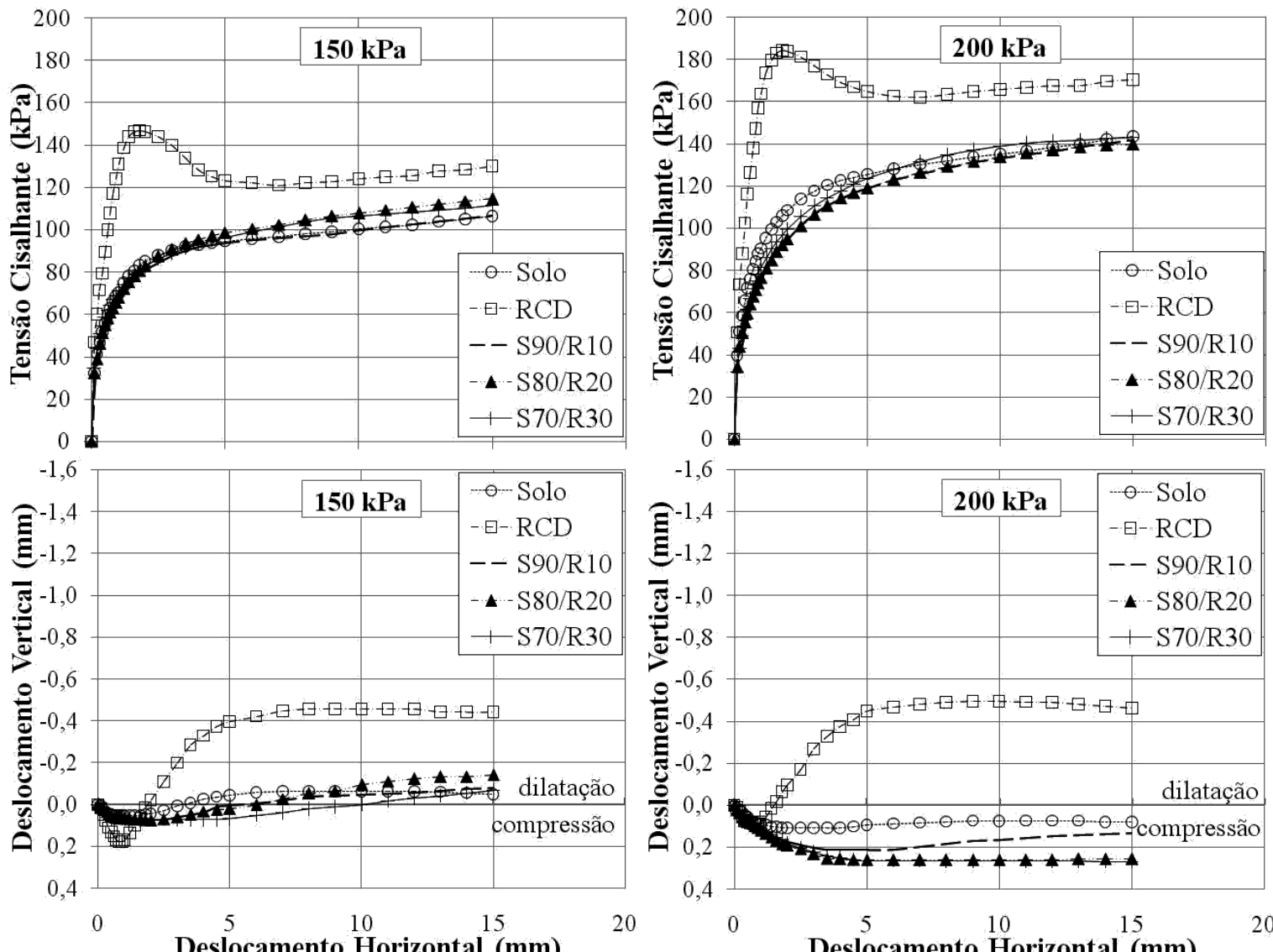

(c)

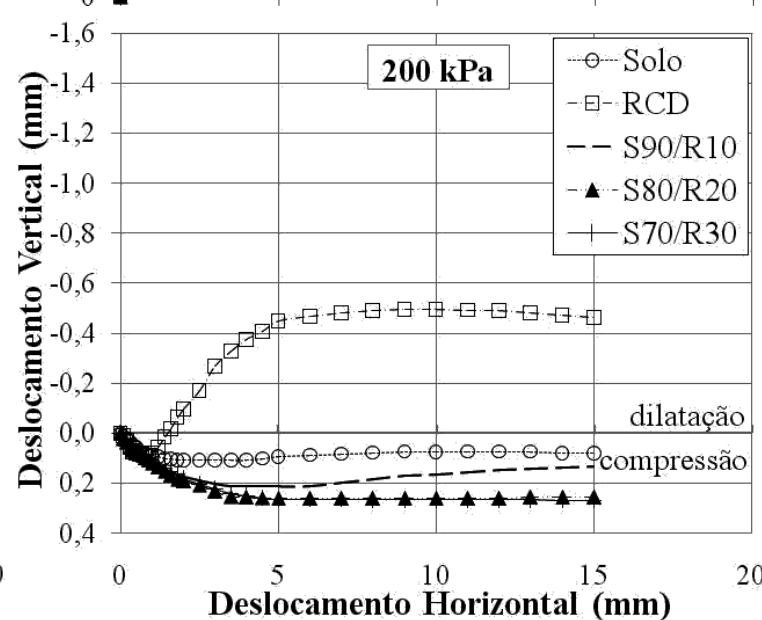

(d)

Figura 7: Resultados dos ensaios de cisalhamento direto para as tensões de 50 (a), 100 (b), 150 (c) e $200 \mathrm{kPa}$ (d). 


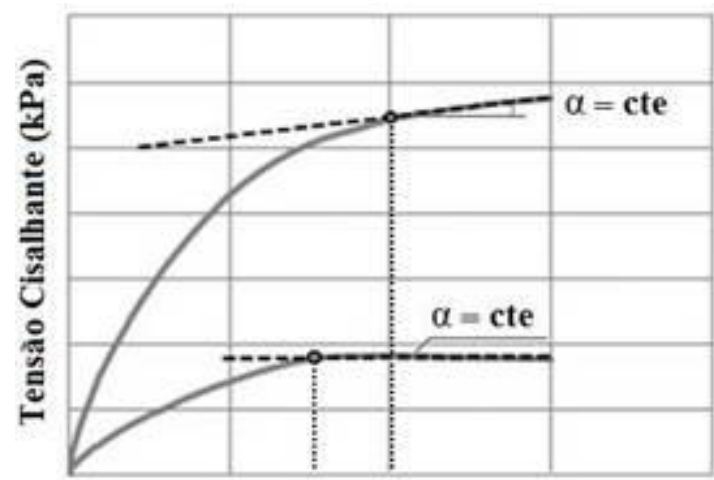

Deslocamento Horizontal (mm)

Figura 8: Definição da tensão cisalhante na ruptura, conforme De Campos e Carrillo [28].

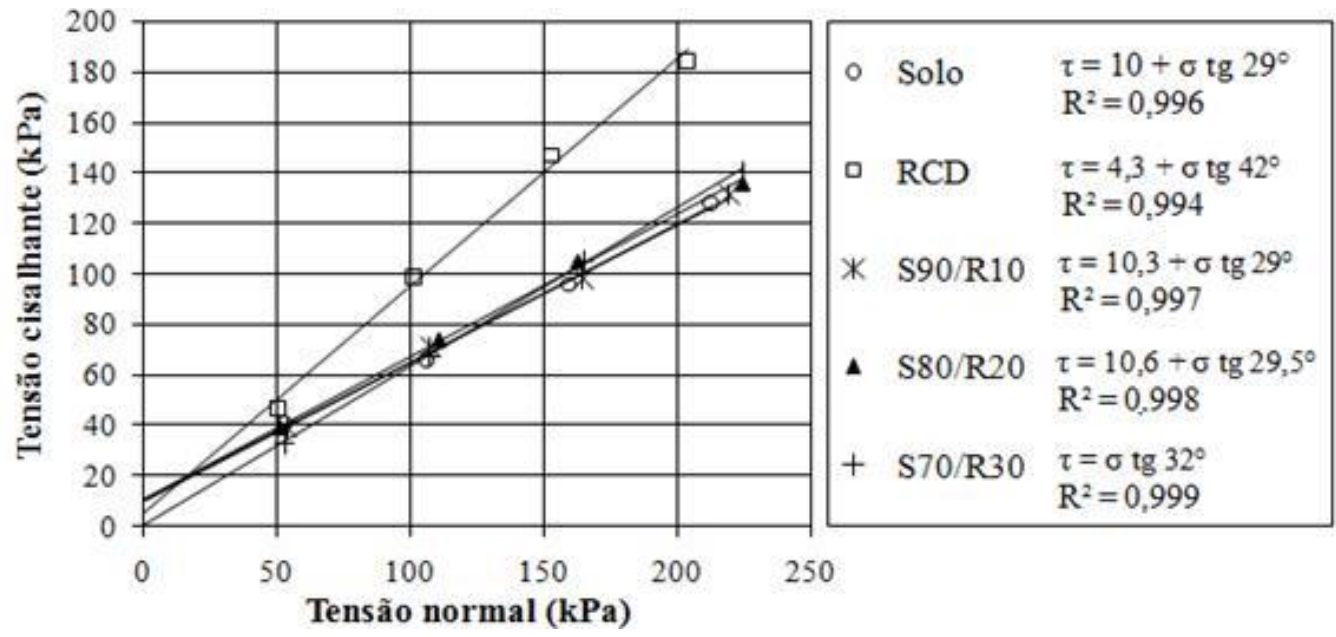

Obs.: $\tau$ - tensão cisalhante; $\sigma$ - tensão normal; $\mathrm{R}^{2}$ - coeficiente de determinação.

Figura 9: Envoltórias de resistência ao cisalhamento.

Tabela 2: Resumo dos resultados obtidos nos ensaios de cisalhamento direto.

\begin{tabular}{|c|c|c|c|c|c|c|}
\hline \multirow{2}{*}{\multicolumn{2}{|c|}{ PARÂMETROS }} & \multicolumn{5}{|c|}{ AMOSTRAS } \\
\hline & & \multirow{2}{*}{$\begin{array}{l}\text { SOLO } \\
53,14 \\
\end{array}$} & \multirow{2}{*}{\begin{tabular}{|l} 
RCD \\
50,60 \\
\end{tabular}} & \multirow{2}{*}{\begin{tabular}{|l|} 
SOLO+10\%RCD \\
53,70 \\
\end{tabular}} & \multirow{2}{*}{\begin{tabular}{|l|} 
SOLO+20\%RCD \\
51,52 \\
\end{tabular}} & \multirow{2}{*}{$\begin{array}{l}\text { SOLO+30\%RCD } \\
53,14 \\
\end{array}$} \\
\hline \multirow{3}{*}{$\sigma_{\mathrm{n}}=50 \mathrm{kPa}$} & $\sigma_{\mathrm{n} \text { corrigida }}(\mathrm{kPa})$ & & & & & \\
\hline & $\tau_{\text {rup }}(\mathrm{kPa})$ & 40,95 & 46,68 & 39,02 & 38,67 & 32,80 \\
\hline & $\mathcal{E}_{\text {rup }}(\mathrm{mm})$ & 7,0 & 1,2 & 7,0 & 3,0 & 6,0 \\
\hline \multirow{3}{*}{$\sigma_{\mathrm{n}}=100 \mathrm{kPa}$} & $\sigma_{\mathrm{n} \text { corrigida }}(\mathrm{kPa})$ & 106,28 & 101,60 & 107,4 & 110,92 & 107,4 \\
\hline & $\tau_{\text {rup }}(\mathrm{kPa})$ & 66,02 & 98,88 & 71,05 & 73,65 & 67,75 \\
\hline & $\mathcal{E}_{\text {rup }}(\mathrm{mm})$ & 6,0 & 1,6 & 7,0 & 10,0 & 7,0 \\
\hline \multirow{3}{*}{$\sigma_{\mathrm{n}}=150 \mathrm{kPa}$} & $\sigma_{\mathrm{n} \text { corrigida }}(\mathrm{kPa})$ & 159,41 & 152,71 & 164,58 & 162,82 & 164,58 \\
\hline & $\tau_{\text {rup }}(\mathrm{kPa})$ & 95,75 & 146,93 & 98,05 & 104,68 & 105,52 \\
\hline & $\mathcal{E}_{\text {rup }}(\mathrm{mm})$ & 6,0 & 1,8 & 9,0 & 8,0 & 9,0 \\
\hline \multirow{3}{*}{$\sigma_{\mathrm{n}}=200 \mathrm{kPa}$} & $\sigma_{\mathrm{n} \text { corrigida }}(\mathrm{kPa})$ & 212,55 & 203,61 & 219,44 & 224,28 & 224,28 \\
\hline & $\tau_{\text {rup }}(\mathrm{kPa})$ & 128,18 & 184,35 & 131,13 & 135,64 & 10,56 \\
\hline & $\mathcal{E}_{\text {rup }}(\mathrm{mm})$ & 6,0 & 1,8 & 9,0 & 11,0 & 11,0 \\
\hline \multicolumn{2}{|l|}{ Coesão (kPa) } & 10 & 4,3 & 10,3 & 10,6 & 0 \\
\hline \multicolumn{2}{|c|}{ Ângulo de atrito (graus) } & 29 & 42 & 29 & 29,5 & 32 \\
\hline
\end{tabular}

Obs.: $\sigma_{\mathrm{n}}-$ tensão normal; $\sigma_{\mathrm{n} \text { corrigida }}$ - tensão normal corrigida; $\tau_{\text {rup }}-$ tensão cisalhante máxima (de ruptura); $\varepsilon_{\text {rup }}-$ deformação de ruptura. 
O solo e as misturas mostram, em sua maioria, curvas de $\tau \mathrm{x}$ dh com crescimento contínuo, sem apresentar um pico de resistência, Figura 7, caracterizando um comportamento do tipo elasto-plástico com enrijecimento.

A amostra de agregado reciclado apresenta curvas $\tau \mathrm{x}$ dh com ocorrência de pico em todas as tensões normais aplicadas, de forma bem definida, Figura 7, indicando que o material é friável, sendo o máximo de resistência (ruptura) atingido na faixa entre 1 e $2 \mathrm{~mm}$ de deslocamento horizontal, Tabela 2. Os valores das tensões cisalhantes máximas do agregado reciclado são bem superiores aos obtidos para o solo e para as misturas de solo com RCD, semelhante ao que foi observado por Santos [9] e Dias [8], que obtiveram valores de tensões cisalhantes maiores para os agregados de RCD utilizados do que para os solos de referência.

Nota-se também que, para o agregado reciclado, após o alcance da máxima tensão cisalhante, há uma posterior redução da mesma em todas as tensões normais, denotando uma resistência residual, contudo esta não atinge patamares constantes até o fim do ensaio, pois se constata um "falso" aumento de resistência a partir de $8 \mathrm{~mm}$ de deslocamento, sendo justificado pela eventual ocorrência de rotação dos principais planos de tensões existentes durante a execução do ensaio.

Todas as amostras apresentaram variações dos deslocamentos verticais, Figura 7, revelando a ocorrência de alterações volumétricas dos corpos de prova durante o ensaio. A dilatação sofre uma redução com o aumento da tensão normal em todas as amostras, sendo os deslocamentos horizontais considerados mínimos nas maiores tensões normais impostas.

O ângulo de atrito do agregado de RCD é superior ao do solo. Para efeitos práticos a inserção de agregado reciclado na matriz do solo argiloso, praticamente, não altera o valor de intercepto coesivo e há um pequeno acréscimo do ângulo de atrito, Tabela 2. A baixa influência do agregado reciclado na parcela de ângulo de atrito dos solos também foi um aspecto observado por Dias [8] e Macedo [10].

No que tange à análise da qualidade de ajuste dos pontos dos gráficos, Figura 9, em torno das respectivas linhas de tendência, foram calculados os coeficientes de determinação $\left(R^{2}\right)$ dos materiais em questão, estando os valores para as envoltórias Morh-Coulomb situados próximo de 1 (um), o que denota um bom ajuste linear das retas de regressão.

O emprego do agregado reciclado de RCD constitui uma alternativa interessante de utilização em obras de engenharia, mitigando os impactos ambientais causados pela exploração de jazidas e pelo descarte inadequado no meio ambiente dos resíduos gerados pelas atividades construtivas.

\section{CONCLUSÕES}

O solo é classificado como areia argilosa (SC) pelo SUCS, é do tipo A-7-6 pelo TRB, apresenta alta plasticidade e possui agregados naturais com grãos subarredondados a arredondados inseridos em uma matriz argilosa, com a presença de flóculos formados pelo arranjo de grãos de areia interligados por partículas de silte e argila de forma densa, conferindo ao mesmo baixa permeabilidade.

$\mathrm{O}$ agregado reciclado de RCD é composto majoritariamente por grãos equivalentes a areia e $21 \%$ de material com tamanho inferior a $0,074 \mathrm{~mm}$, equipara-se, segundo o SUCS, a um solo do grupo SM (areia siltosa), se enquadra na classe A-2-4 pelo sistema TRB, é não plástico, possui uma massa específica real dos grãos próxima a do solo estudado e uma microestrutura granular com pequenos flóculos espaçados.

A inserção de agregado reciclado provocou mudanças no solo referente às características físicas, tais como: redução das frações < $0,074 \mathrm{~mm}$, da plasticidade, da porosidade e da umidade ótima, aumento do peso específico seco máximo e melhoria das características para aplicação como subleito de pavimentos, chegando admitir um comportamento de excelente a bom, conforme o TRB, a medida que o teor de agregado de RCD dentro da matriz aumenta.

A adição do agregado de RCD acentuou as reentrâncias e saliências na superfície do solo, implicando em agregações de partículas finas do solo com as partículas do RCD, formando flóculos e grumos de maiores dimensões.

A condutividade hidráulica do solo foi elevada em mais de 13 vezes quando da inserção do agregado de RCD, variando a ordem de magnitude da sua permeabilidade de $10^{-10}$ para $10^{-8} \mathrm{~m} / \mathrm{s}$. Assim, as misturas podem ser empregadas em bases e coberturas de aterros de resíduos não perigosos, como os resíduos sólidos municipais.

O comportamento elasto-plástico das curvas de tensão cisalhante versus deslocamento horizontal do solo não se altera com a adição do agregado reciclado. As tensões cisalhantes máximas do agregado de RCD são as mais elevadas dentre os materiais estudados, indicando um ângulo de atrito de $42^{\circ}$, superior ao do solo 
$\left(29^{\circ}\right)$ e ao das misturas com 10,20 e $30 \%$ de agregado reciclado $\left(29^{\circ}, 29,5^{\circ}\right.$ e $32^{\circ}$, respectivamente).

Ressalta-se que, além de a inserção do agregado reciclado de RCD aumentar a permeabilidade e praticamente não alterar a resistência ao cisalhamento do solo compactado, está se reduzindo um passivo ambiental pelo efeito da reutilização do agregado reciclado proveniente de resíduos da Indústria da Construção Civil.

\section{AGRADECIMENTOS}

Os autores agradecem ao Programa de Fortalecimento Acadêmico da Universidade de Pernambuco pelo apoio financeiro concedido por meio da bolsa de estudo e a empresa Ciclo Ambiental por ceder o agregado reciclado de RCD utilizado.

\section{BIBLIOGRAFIA}

[1] BRASIL, Lei $\mathrm{n}^{\circ}$ 12.305: Institui a política nacional de resíduos sólidos, altera a lei $n^{\circ} 9.605$, de 12 de fevereiro de 1998, e dá outras providencias, Brasília, 2010.

[2] GUSMÃO, A. D., Manual de gestão dos resíduos da construção civil, 1 ed., Camaragibe, CCS Gráfica Editora, 2008.

[3] BAPTISTA, C. F. N., Ensaios fundamentais para a pavimentação e dimensionamentos dos pavimentos flexíveis, v. 1, 2 ed., Porto Alegre, Globo, 1976.

[4] BUDINSKI, K. G., Engineering materials: properties and selection. 5 ed., New Jersey, Prentice Hall International, 1996.

[5] MAIA, E. S., AGUIAR, M. F. P., OLIVEIRA, F. H. L., "Estudo de melhoramento de solo com utilização de resíduo de indústria de celulose”, Revista Tecnologia, v. 35, n. 1 e 2, pp. 78-88, dez. 2014.

[6] ASSOCIAÇÃO BRASILEIRA DE NORMAS TÉCNICAS, NBR 15116: agregados reciclados de resíduos da construção civil: utilização em pavimentação e preparo de concreto sem função estrutural: requisitos, Rio de Janeiro, 2004.

[7] FERREIRA, M. C., THOMÉ, A., "Utilização de resíduo da construção e demolição como reforço de um solo residual de basalto, servindo como base de fundações superficiais", Teoria e Prática na Engenharia Civil, n. 18, pp. 1-12, nov. 2011.

[8] DIAS, M. C. C., Viabilidade do uso de solo tropical e resíduo de construção civil em sistemas de cobertura de aterro sanitário, Dissertação de M. Sc., EEC/UFG, Goiânia, GO, Brasil, 2014.

[9] SANTOS, E. C. G., Aplicação de resíduos de construção e demolição reciclados (RCD-R) em estruturas de solo reforçado, Dissertação de M.Sc., EESC/USP, São Carlos, SP, Brasil, 2007.

[10] MACEDO, M. C., Investigação sobre o comportamento geomecânico de misturas de solo com resíduos de pneus e resíduos de construção e demolição, Dissertação de M.Sc., POLI/UPE, Recife, Brasil, PE, 2016.

[11] TAYLOR, G. D., Materials in construction, 2 ed., London, Longman Scientific \& Technical, 1994.

[12] PEREIRA, R.S.; MACHADO, C. C., CARVALHO, C. A. B. "Uso de resíduos em pavimentos de estradas florestais: caracterização de solos e misturas solo-grits”, Revista Árvore, v. 30, n. 4, pp. 629-635, jul./ago. 2006.

[13] ASSOCIAÇÃO BRASILEIRA DE NORMAS TÉCNICAS, NBR 10004: Resíduos sólidos: classificação, Rio de Janeiro, 2004.

[14] ASSOCIAÇÃO BRASILEIRA DE NORMAS TÉCNICAS, NBR 7181: Solo: análise granulométrica, Rio de Janeiro, 2016.

[15] ASSOCIAÇÃO BRASILEIRA DE NORMAS TÉCNICAS, NBR 6508: Grãos de solos que passam na peneira de 4,8 mm: determinação da massa específica, Rio de Janeiro, 1984.

[16] ASSOCIAÇÃO BRASILEIRA DE NORMAS TÉCNICAS, NBR 6459: Solo: determinação do limite de liquidez, Rio de Janeiro, 2016.

[17] ASSOCIAÇÃO BRASILEIRA DE NORMAS TÉCNICAS, NBR 7180: Solo: determinação do limite de plasticidade, Rio de Janeiro, 2016.

[18] ASSOCIAÇÃO BRASILEIRA DE NORMAS TÉCNICAS, NBR 7182: Solo: ensaio de compactação, Rio de Janeiro, 2016. 
[19] ASSOCIAÇÃO BRASILEIRA DE NORMAS TÉCNICAS, NBR 14545: Solo: determinação do coeficiente de permeabilidade de solos argilosos a carga variável, Rio de Janeiro, 2000.

[20] AMERICAN SOCIETY FOR TESTING AND MATERIALS, D 3080: Standard test method for direct shear testo f soils under consolidated drained conditions, West Conshohocken, 2004.

[21] AMERICAN SOCIETY FOR TESTING AND MATERIALS, D 422: Standard test method for particlesize analysis of soils, West Conshohocken, 2007.

[22] MACEDO, T. F., Análise do desempenho mecânico da mistura agregado reciclado-solo-fibra-cimento para pavimentação, Dissertação de M.Sc., POLI/UPE, Recife, PE, Brasil, 2013.

[23] UNITED STATES ENVIRONMENTAL PROTECTION AGENCY, Solid waste disposal facility criteria: technical manual, Washington, 1993.

[24] CAPUTO, H. P., CAPUTO, A. N., Mecânica dos solos e suas aplicações: fundamentos, v. 1, 7 ed., Rio de Janeiro, LTC, 2015.

[25] AUSTIN, T., “Landfill-cover conflit”, Civil Engineering, v. 62, n. 12, pp. 70-71, Dec. 1992.

[26] DANIEL, D. E., KOERNER, R. M., Geotechnical pratice waste disposal, 1 ed., London, Chapman \& Hall, 1993.

[27] ASSOCIAÇÃO BRASILEIRA DE NORMAS TÉCNICAS, NBR 13896: Aterros de resíduos não perigosos: critérios para projeto, implantação e operação, Rio de Janeiro, 1997.

[28] CAMPOS, T. M. P., CARRILLO, C. W., "Direct shear testing on na unsaturated soil from rio de janeiro", In: Proceedings of the International Conference on Unsaturated Soils (UNSAT'95), v. 1, pp. 31-38, Paris, France, Sep. 1995.

\section{ORCID}

Silvio Romero de Melo Ferreira

https://orcid.org/0000-0002-5760-1494

Stela Fucale Sukar

https://orcid.org/0000-0002-7536-498X

Aline Cátia da Silva

https://orcid.org/0000-0003-4664-6256 